\title{
Employment of different spectroscopic tools for the investigation of chromium(VI) oxidation of acetaldehyde in aqueous micellar medium
}

\author{
SUSANTA MALIK ${ }^{\mathrm{a}}$, ANIRUDDHA GHOSH ${ }^{\mathrm{a}}$, PINTU SAR ${ }^{\mathrm{a}}$, \\ MONOHAR HOSSAIN MONDAL ${ }^{\mathrm{a}, \mathrm{b}}$, KALACHAND MAHALI ${ }^{\mathrm{c}}$ and BIDYUT SAHA ${ }^{\mathrm{a}, *}$ \\ ${ }^{a}$ Homogeneous Catalysis Laboratory, Department of Chemistry, The University of Burdwan, Burdwan, \\ West Bengal 713 104, India \\ ${ }^{\mathrm{b}}$ Chemical Sciences Laboratory, Government General Degree College, Singur, Hooghly, West Bengal 712 304, \\ India \\ ${ }^{c}$ Department of Chemistry, University of Kalyani, Kalyani, West Bengal 741 235, India \\ E-mail: b_saha31@rediffmail.com
}

MS received 27 February 2017; revised 5 April 2017; accepted 6 April 2017

\begin{abstract}
Different spectroscopic methods have been applied to investigate the chromic acid oxidation of acetaldehyde in aqueous media, catalysed by surfactants. Three representative heteroaromatic nitrogen base promoters, 2-picolinic acid (PA), 2,2'-bipyridine (bpy) and 1,10-phenanthroline (phen), have been associated along with surfactants as promoters to the kinetic study. Comparative studies of unpromoted and promoted reactions invoked that 2,2'-bipyridine produced maximum rate enhancement. The mechanism of the reaction path has been proposed with the help of kinetic results and spectroscopic studies. The observed net enhancement of rate effects has been explained with scientific manipulations and data obtained. The combination of TX-100 and1,10-phenanthroline is found to be most effective for acetaldehyde oxidation.
\end{abstract}

Keywords. Kinetics; oxidation; acetaldehyde; micelle; catalysis.

\section{Introduction}

The quest of modifying conventional electron transfer chemistry to more 'Environmental-friendly' green chemistry leads to the development in conventional methodology and more greener alternatives. ${ }^{1,2}$ For the most frequently used organic reactions, sustainable development it is important for synthesizing civilizationfriendly compounds. ${ }^{3}$ In this present work, simple reagents have been employed, which have application in industrial engineering and chemistry. Acetaldehyde is a noxious, volatile organic compound that originates from a variety of domestic and industrial sources. ${ }^{4}$ Among its diverse utilization, the manufacture of acetic acid is notable and most common. ${ }^{5,6}$ It also has its use in the preparation of phenolic resins in the manufacture of dyes and rubber, while the product acetic acid, first reported ${ }^{7}$ in 1926, has earned a prominent place in modern day chemical world as a solvent, as a precursor for organic synthesis, in the production of vinyl acetate and various types of polyesters. ${ }^{8}$

\footnotetext{
*For correspondence
}

The mechanistic aspects of oxidation of different aliphatic and aromatic aldehydes by different transition metal ions in aqueous acid media have already been reported, but the conventional methods are less ecofriendly. ${ }^{9-12}$ The reagent hexavalent chromium is one of the most strong oxidizing agents in chemistry and industry and immensely useful. $\mathrm{Cr}(\mathrm{VI})$ with reduction potential $\left(\mathrm{E}^{0}=1.33 \mathrm{~V}\right)$ oxidizes a variety of oxidizable functional groups. Application of $\mathrm{Cr}(\mathrm{VI})$ containing reagents like quinolinium chlorochromate, ${ }^{13}$ quinolinium fluorochromate, ${ }^{14}$ tributylammonium chlorochromate, ${ }^{15}$ quinoliniumdichromate, ${ }^{16-18}$ and tripropylammonium halochromates ${ }^{19}$ was studied over the years for the oxidation of countless organic substrates, but the applications are facing questions due to the use of hazardous organic solvents such as dichloromethane, dimethyl formamide, acetone, etc. ${ }^{20,21}$ In the search for well behaving prototypes, surfactants have proved themselves as good green alternates, as homogeneous catalysts ${ }^{2}$ in "green chemistry". 1,22 The present investigation is the homogeneous catalytic oxidation of acetaldehyde to acetic acid in aqueous media, where surfactants function as catalysts. The very low reactiontime, i.e. fast kinetics, with satisfactory high yield of product, 
which requires no supplement of extreme and drastic condition proved it to be a greener approach. ${ }^{23}$ There has been a flow of interest on catalysis of reactions by surfactant micelles with a view of their extensive applications in chemical, industrial, pharmaceutical, environmental and biological fields. ${ }^{24-26}$ A systematic study of associated systems comprising electron transfer reaction and micelle formation process of surfactants might therefore be helpful to understand the electron transport system in catalysis. ${ }^{27-29}$ The oxidation of acetaldehyde by $\mathrm{Cr}(\mathrm{VI})$ in the micellar system also appears to be an appropriate model reaction for presenting the mechanism of micellar catalysis in green aqueous solvent.

\section{Experimental}

\subsection{Materials and reagents}

Acetaldehyde (99.5\%, Sigma Aldrich), $\mathrm{K}_{2} \mathrm{Cr}_{2} \mathrm{O}_{7}$ (99.9\%, $\mathrm{BDH}), \mathrm{H}_{2} \mathrm{SO}_{4}$ (98\%, Merck), Picolinic acid (PA) $(99 \%$, Sigma Aldrich), 2,2'-bipyridine (bipy) (99\%, Spectrochem, India), 1,10-phenanthroline (phen) (99.5\%, Merck), sodium dodecyl sulfate (SDS) (SRL, India), $N$-cetylpyridinium chloride (CPC) (SRL, India), Triton X-100 (TX-100) (SRL, India) and $\mathrm{D}_{2} \mathrm{O}$ (Sigma Aldrich) and double distilled water were used. All other used chemicals have been purchased in their highest purity state.

\subsection{Instrumentation}

The necessary solutions were prepared by using a Digital Ultrasonic Cleaner CD 4820 sonicator and Z206A, Hermle Labortechnik $\mathrm{GmbH}$ was used for centrifugation. UV-Vis spectra were recorded on a UV-Vis 2450 spectrophotometer (Shimadzu) equipped with a temperature controller (TCC SHIMADZU). ${ }^{1} \mathrm{H}$-NMR spectra were recorded on a Bruker Ascend $500 \mathrm{MHz}$ spectrometer at room temperature. DLS studies were performed using Malvern Zetasizer Nano ZS-90 instrument. The infrared spectrum was recorded on a FTIR spectrometer (Shimadzu Prestige-21, Japan) in the region $4000-400 \mathrm{~cm}^{-1}$ with a resolution of $4.0 \mathrm{~cm}^{-1}$ at $30^{\circ} \mathrm{C}$.

\subsection{Procedure and kinetics measurements}

All kinetic runs were accomplished under pseudo-first order conditions by keeping the concentration of substrate (acetaldehyde) in large excess ( $\geq 15$-fold) relative to the oxidant $\left(\mathrm{K}_{2} \mathrm{Cr}_{2} \mathrm{O}_{7}\right)$ concentration. The oxidation reaction was initiated by adding requisite quantities of the oxidant solution placed separately in the mixture containing the substrate and $\mathrm{H}_{2} \mathrm{SO}_{4}$ in the presence and absence of surfactants (SDS, CPC, TX-100) and promoters (PA, bipy, phen). The acid and other necessary chemicals were separately thermostated at $30^{\circ} \mathrm{C}$ $\left( \pm 0.1^{\circ} \mathrm{C}\right)$. Progress of the reaction was monitored with a UVVis spectrophotometer in a quartz cuvettes of $1 \mathrm{~cm}$ path length by following the absorbance decay of $\mathrm{Cr}(\mathrm{VI})$ at $450 \mathrm{~nm}$ at regular time intervals.

\subsection{Product analysis and stoichiometry}

After completion, the reaction mixture was taken in a round bottom flask connected with fractional distillation tube and then lyophilized the distillated product. The formation of product was further confirmed by the FTIR analysis and mass spectroscopy (Figures S1 and S2 in Supplementary Information). Due to the excess concentration (pseudo-first order condition) of substrate (acetaldehyde) present in the reaction mixture as compared to $\mathrm{Cr}(\mathrm{VI})$, it is expected that the $\mathrm{Cr}(\mathrm{VI})$ ion will be totally reduced to $\mathrm{Cr}(\mathrm{III})$ at the end of reaction. There is no possibility of hexavalent chromium mixing into the industrial effluent through drainage, if the reaction is scaled up. The existence of $\mathrm{Cr}(\mathrm{III})$ in the product mixture was established from the absorption maximum at $580 \mathrm{~nm}$ in this work and also supported from earlier reports. ${ }^{16,23,30}$

The stoichiometry of the reaction was determined by spectrophotometric titration. Several kinetic runs were carried out by taking [acetaldehyde] $>>$ [chromium(VI)] at fixed $\left[\mathrm{H}^{+}\right]$ and kept the reaction mixture for $48 \mathrm{~h}$ at $30^{\circ} \mathrm{C}$. After completion of the reaction, the unconsumed oxidant was determined spectrophotometrically. The overall stoichiometry of the oxidation can be represented as:

$$
\begin{aligned}
& 3 \mathrm{CH}_{3} \mathrm{CHO}+2 \mathrm{HCro}_{4}^{-}+8 \mathrm{H}^{+} \longrightarrow 3 \mathrm{CH}_{3} \mathrm{COOH} \\
& +2 \mathrm{Cr}^{3}+5 \mathrm{H}_{2}
\end{aligned}
$$

2.4a FTIR spectrum: The product acetic acid was confirmed by IR spectrum. IR spectral analysis of the oxidized product (Figure $\mathrm{S} 1$ in $\mathrm{SI}$ ) showed the $\mathrm{C}=\mathrm{O}$ stretch at $1700 \mathrm{~cm}^{-1}$ and C-O stretch at $1300 \mathrm{~cm}^{-1}$ and a broad band around $3000 \mathrm{~cm}^{-1}$ corresponding to the $\mathrm{O}-\mathrm{H}$ in carboxylic acid.

2.4b Mass spectrum: The High Resolution Mass spectrum of oxidized product of acetaldehyde is presented in Figure S2 (in SI). The mass spectral analysis of the product gave the molecular ion peak at $\mathrm{m} / \mathrm{z} 60.19$ along with the isotopic peak at $\mathrm{m} / \mathrm{z} 62.17$. The acetic acid precursor ions were found at $\mathrm{m} / \mathrm{z} 61.14$ in the positive ion mode. All these identifications confirmed that the product was acetic acid.

\subsection{Test for free radicals}

The addition of acrylonitrile solution $(40 \%, \mathrm{~V} / \mathrm{V})$ to the reaction mixture under the protection of nitrogen gas was carried out gently. A lot of white deposition was found, indicating that the reaction system can initiate polymerization of acrylonitrile. ${ }^{31,32}$ The appearance of the precipitate proves the generation of free radicals in the reaction. 

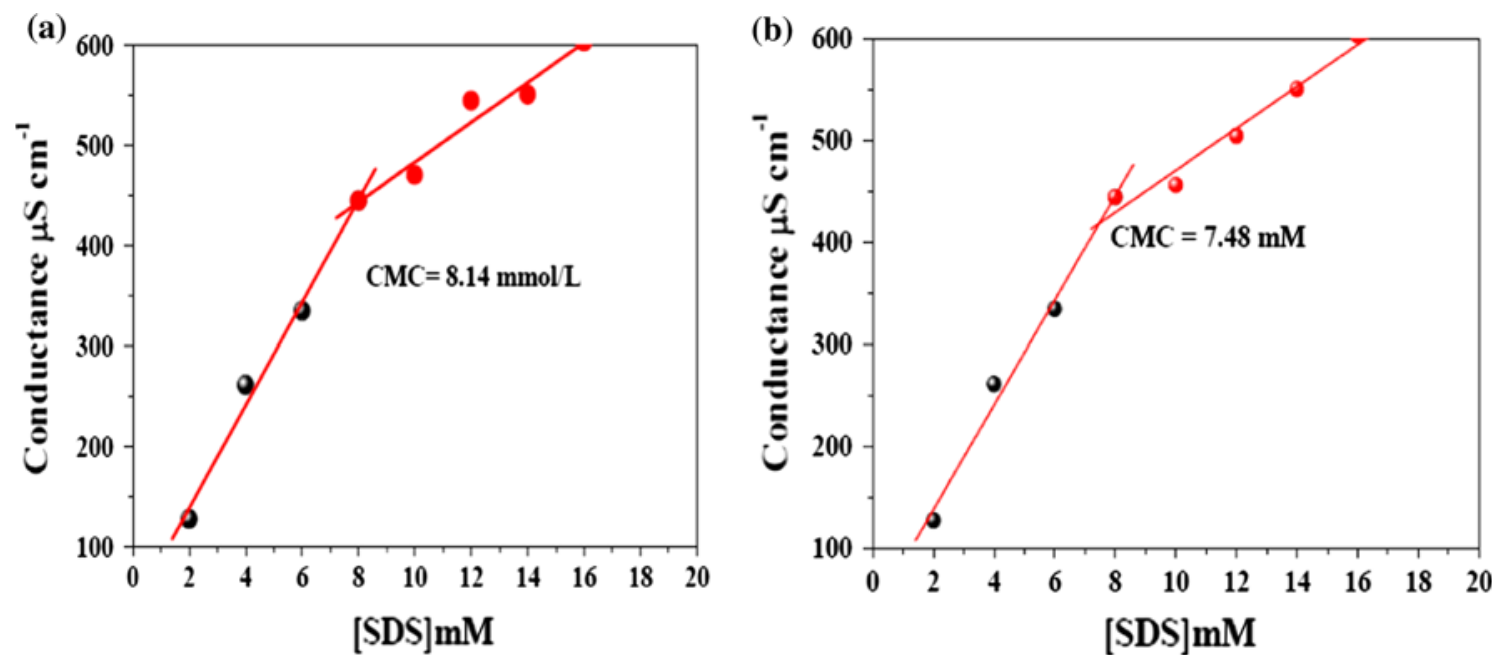

Figure 1. Conductance versus $[\mathrm{SDS}]$ plot at $30^{\circ} \mathrm{C}$ : a in water; $\mathbf{b}$ in water + acetaldehyde.

\subsection{Measurements of critical micelle concentration (CMC) of $S D S$}

The critical micelle concentration (cmc) values of the SDS in the presence and absence of acetaldehyde were obtained from conductometry by plotting conductance vs. [SDS]. Experiments were done under different conditions, i.e., solvent water and water + acetaldehyde $\left(2.0 \times 10^{-3} \mathrm{~mol} \cdot \mathrm{dm}^{-3}\right)$, and the respective cmc values were $8.14^{33}$ and $7.48 \mathrm{mmol} / \mathrm{L}$ (Figure 1a, b). CMC of SDS is reduced (from $8.14 \mathrm{mM}$ to $7.4 \mathrm{mM}$ ) due to the hydrophobic interaction caused between $\mathrm{CH}_{3} \mathrm{CHO}$ molecule and the alkyl chain of SDS surfactant.

\section{Results and Discussion}

The progress of the reaction was followed spectrophotometrically at $450 \mathrm{~nm}$ by monitoring the decrease in absorbance of $\mathrm{Cr}(\mathrm{VI})$ at regular time interval. The pseudo-first order rate constants $\left(k_{\mathrm{obs}}, \mathrm{s}^{-1}\right)$ have been calculated from the slope of plots of $\ln (\mathrm{A})_{450}$ versus time (t). The observed pseudo-first order rate constants, $k_{\text {obs }}\left(\mathrm{s}^{-1}\right)$ for each reaction are given in Table S1 (in Supplementary Information). The data in Table $\mathrm{S} 1$ show that $k_{\text {obs }}$ values for SDS, CPC and TX-100 micelle-catalyzed reaction are greater than that of the corresponding uncatalyzed reaction. This observation is also true for promoted path compared to the unpromoted path. It has been observed that the rate of organic transformation can be significantly improved in the aqueous micellar solutions of ionic surfactants (Figure 2).

The reaction mixtures were scanned in the range of 250-650 nm for both presence and absence of promoter and surfactant at regular time intervals ( $3 \mathrm{~min}$ ) to follow the appearance of the reaction intermediates (if any) and the product. The scanned spectra (Figures S3 in SI) indi-

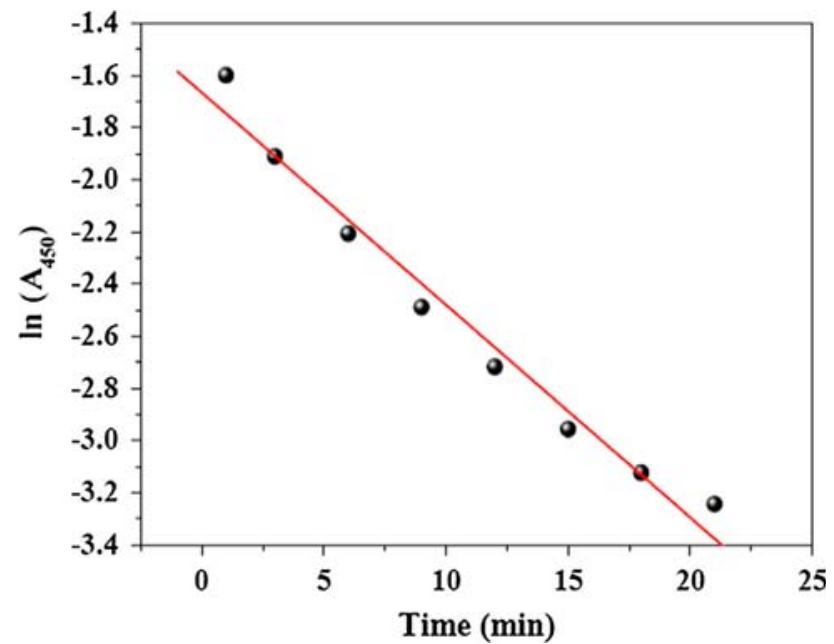

Figure 2. Representative first-order plot for $\mathrm{Cr}$ (VI) oxidation of acetaldehyde in phen-surfactant catalyzed path at $30^{\circ} \mathrm{C}$. $[\mathrm{Cr}(\mathrm{VI})]_{\mathrm{T}}=5 \times 10^{-4} \mathrm{~mol} \mathrm{dm}^{-3},\left[\mathrm{H}_{2} \mathrm{SO}_{4}\right]_{\mathrm{T}}=0.5 \mathrm{~mol}$ $\mathrm{dm}^{-3}, \quad$ [Acetaldehyde $]_{\mathrm{T}}=75 \times 10^{-3} \mathrm{~mol} \mathrm{\textrm {dm } ^ { - 3 }}$, $[\mathrm{TX}-100]_{\mathrm{T}}=2 \times 10^{-2} \mathrm{~mol} \mathrm{dm}^{-3},[\text { phen }]_{\mathrm{T}}=75 \times 10^{-4} \mathrm{~mol}$ $\mathrm{dm}^{-3}$. T refers to Total concentration. $\mathrm{A}_{450}=$ Absorbance at $450 \mathrm{~nm}$ and molar extinction coefficient $(\varepsilon)$ of $\mathrm{Cr}(\mathrm{VI})=404 \mathrm{dm}^{3} \mathrm{~mol}^{-1} \mathrm{~cm}^{-1}$ at $450 \mathrm{~nm}$.

cates the gradual disappearance of $\mathrm{Cr}(\mathrm{VI})$ species and appearance of $\mathrm{Cr}(\mathrm{III})$. The same was also observed for micelle-catalyzed reactions in the presence and absence of promoter.

Under the experimental condition, the color of the final solution in absence of promoter is pale blue (Figure S4a in SI, $\lambda_{\max }=441 \mathrm{~nm}$ and $580 \mathrm{~nm}$ ) and the two peaks are responsible for following two transitions: ${ }^{34-36}$ ${ }^{4} \mathrm{~A}_{2 \mathrm{~g}}(\mathrm{~F}) \rightarrow{ }^{4} \mathrm{~T}_{2 \mathrm{~g}}(\mathrm{~F})$ and ${ }^{4} \mathrm{~A}_{2 \mathrm{~g}}(\mathrm{~F}) \rightarrow{ }^{4} \mathrm{~T}_{1 \mathrm{~g}}(\mathrm{~F})$. The absorption spectrum of the final solution in the absence of promoter is identical with the spectrum of pure chromic sulfate solution in sulfuric acid media. The 
color of the final solution in presence of promoters under the identical conditions is pale violet [Figures S4(bd), $\lambda_{\max }=555,545$ and $567 \mathrm{~nm}$ for phen, bipy and PA-promoted reactions, respectively] due to the existence of different [Cr(III)-promoter] species. For the promoted reaction, there is a blue shift for the peak due to the transition ${ }^{4} \mathrm{~A}_{2 \mathrm{~g}}(\mathrm{~F}) \rightarrow{ }^{4} \mathrm{~T}_{2 \mathrm{~g}}(\mathrm{~F})$ compared to the final solution of the without promoter path. This blue shift is due to the presence of the strong field donor site, i.e., heteroaromatic $\mathrm{N}$-donor site of the promoter. For $\mathrm{Cr}(\mathrm{III})$-aqueous species, the band at $260 \mathrm{~nm}$ due to ${ }^{4} \mathrm{~A}_{2 \mathrm{~g}}(\mathrm{~F}) \rightarrow{ }^{4} \mathrm{~T}_{1 \mathrm{~g}}(\mathrm{P})$ transition appears as a shoulder on high energy charge transfer band. ${ }^{36,37}$ The scanned spectrum (Figure S3c) indicates the gradual disappearance of $\mathrm{Cr}(\mathrm{VI})$ species and appearance of $\mathrm{Cr}$ (III) species with an isosbestic point at $\lambda=515 \mathrm{~nm}$ for the promoter reaction (TX-100 and phen-promoted scan). Observation of this single isosbestic point indicates very low concentration of $\mathrm{Cr}(\mathrm{IV})$ and $\mathrm{Cr}(\mathrm{V})$ intermediates under the experimental condition.

\subsection{Influence of promoter}

The promoters act as chelating having one or more nitrogen atom in the aromatic ring and observed as similar in their reactivity in most of the metal based oxidation reaction. Generally, they are strong bases and act as effective oxidation catalyst. The rate of the reaction increases with introduction of heteroaromatic nitrogen base promoters (PA, bipy and phen).

\subsection{Influence of surfactant on reaction rate}

The rate of oxidation of acetaldehyde was found to be enhanced in presence of both the TX-100 and SDS in the medium. A positively charged $\mathrm{Cr}(\mathrm{VI})$-promoter (active oxidant) species formed during the oxidation is susceptible for electrostatic interaction with the negatively charged SDS micelle. As a consequence the local concentration effect of the reactant molecule in the Stern-region of SDS micelle significantly participate to increase the rate of reaction in SDS micellar medium than that in aqueous medium. ${ }^{23}$ The hydrophilic interaction between nonionic (TX-100) micelle and either reactants or reaction intermediate and local concentration effect appeared to be the probable source of micellar catalysis.

In the unpromoted path, protonation of the neutral ester is very important for the rate of the reaction. Partitioning of neutral ester in both ionic and nonionic surfactants is almost equally probable for unpromoted path. Partitioning of proton is maximum in SDS due to electrostatic attraction. So, the rate is higher in SDS compared to CPC (Table S1 in SI). The active oxidant $\mathrm{Cr}(\mathrm{VI})$-phen complex reacts with the substrate to form a ternary complex which experiences a redox decomposition in a rate determining step giving rise to the organic product. ${ }^{12,23} \mathrm{As} \mathrm{Cr}(\mathrm{VI})$-phen is a giant molecule, electrostatic attraction is not operating smoothly. For promoted reaction path, the rate is maximum in TX100 followed by SDS (Table S1 in SI). The higher reaction rate observed in TX-100 micelle is most probably due to the larger space available for accumulating the maximum number of $\mathrm{Cr}(\mathrm{VI})$-promoter and substrate molecules in TX-100 micelle compared to SDS micelle.

\subsection{Mechanism and rate of the reaction}

The reaction is first order dependent on both [acetaldehyde] and oxidant [Cr(VI)], but it is interesting that the reaction shows second order dependence on $\left[\mathrm{H}^{+}\right]{ }^{38-41}$ With the help of several kinetic and experimental findings of the reaction progress, the reaction is mainly divided into unpromoted and promoted pathways.

The oxidation of acetaldehyde by $\mathrm{Cr}(\mathrm{VI})$ in presence of SDS and TX-100 indicates that the reaction medium may contain both the neutral $\left(\mathrm{H}_{2} \mathrm{CrO}_{4}\right)$ as well as cationic oxidant species $\left(\mathrm{HCrO}_{3}^{+}\right)$. Under the experimental conditions $\mathrm{H}_{2} \mathrm{CrO}_{4}$ and $\mathrm{HCrO}_{3}^{+}$species exist in significant concentrations (equation 5). But in the presence of high acid concentration $\left(\left[\mathrm{H}^{+}\right]=0.5 \mathrm{~mol} \mathrm{dm}^{-3}\right)$ the existence of $\mathrm{HCrO}_{4}^{-}$species is maximum in the following equlibrium (equation 6).

$$
\begin{aligned}
& \mathrm{H}_{2} \mathrm{CrO}_{4}+H^{+} \rightleftharpoons \mathrm{HCrO}_{3}+\mathrm{H}_{2} \mathrm{O} \\
& \mathrm{Cr}_{2} \mathrm{O}_{7}^{2-}+\rightleftharpoons 2 \mathrm{HCrO}_{4}^{-}
\end{aligned}
$$

According to Ansari et al., ${ }^{42}$ as the $\left[\mathrm{H}^{+}\right]$increases, the percentage of $\mathrm{H}_{2} \mathrm{CrO}_{4}$ species increases which, in turn, increases the reaction rate.

From the Scheme 1,

$$
\begin{aligned}
\mathrm{K}_{1} & =\frac{[\text { Neutral ester }]}{\text { [acetaldehyde }]\left[\mathrm{H}^{+}\right]\left[\mathrm{HCrO}_{4}^{-}\right]} \\
\mathrm{K}_{2} & =\frac{[\text { Protonated ester }]}{[\text { Neutral ester }]\left[\mathrm{H}^{+}\right]} \\
\text {rate } & =\frac{\mathrm{d}[\text { acetic acid }]}{\mathrm{dt}}=k_{2}[\text { Protonated ester }] \\
& =k_{2} \mathrm{~K}_{2}[\text { Neutral ester }]\left[\mathrm{H}^{+}\right] \\
& \left.=k_{2} \mathrm{~K}_{1} \mathrm{~K}_{2} \text { [acetaldehyde }\right]\left[\mathrm{HCrO}_{4}^{-}\right]\left[\mathrm{H}^{+}\right]^{2}
\end{aligned}
$$

According to the stoichiometric equation for the overall reaction we may write as:

$$
\begin{aligned}
& -\frac{1}{2} \frac{\mathrm{d}\left[\mathrm{HCrO}_{4}^{-}\right]}{\mathrm{dt}}=\frac{1}{3} \frac{\mathrm{d}[\text { acetic acid }]}{\mathrm{dt}} \\
& \left.-\frac{1}{2} \frac{\mathrm{d}\left[\mathrm{HCrO}_{4}^{-}\right]}{\mathrm{dt}}=\frac{1}{3} k_{2} \mathrm{~K}_{1} \mathrm{~K}_{2} \text { [acetaldehyde }\right]\left[\mathrm{HCrO}_{4}^{-}\right]\left[\mathrm{H}^{+}\right]^{2}
\end{aligned}
$$




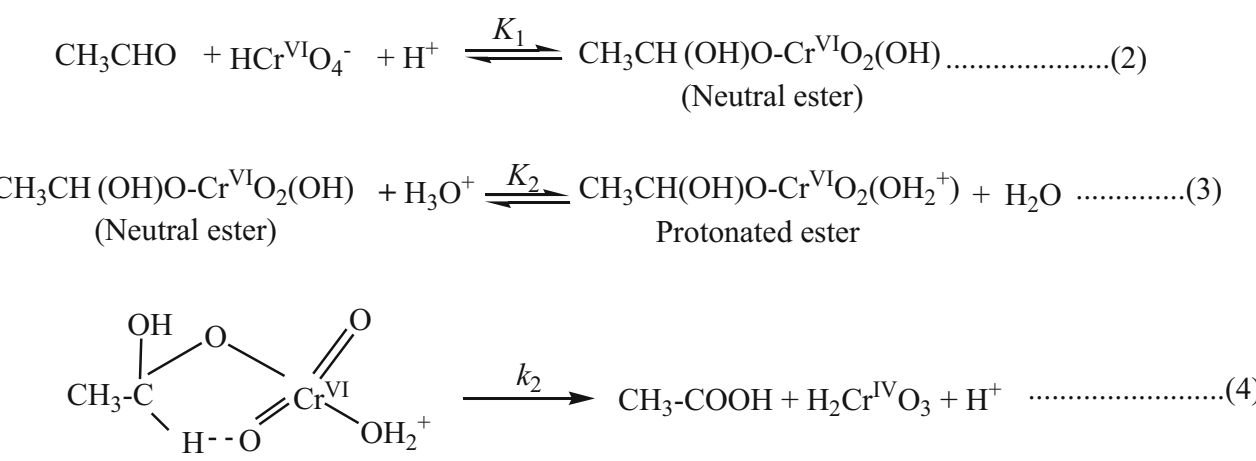

Scheme 1. $\mathrm{Cr}(\mathrm{VI})$ oxidation of acetaldehyde in the absence of promoter.

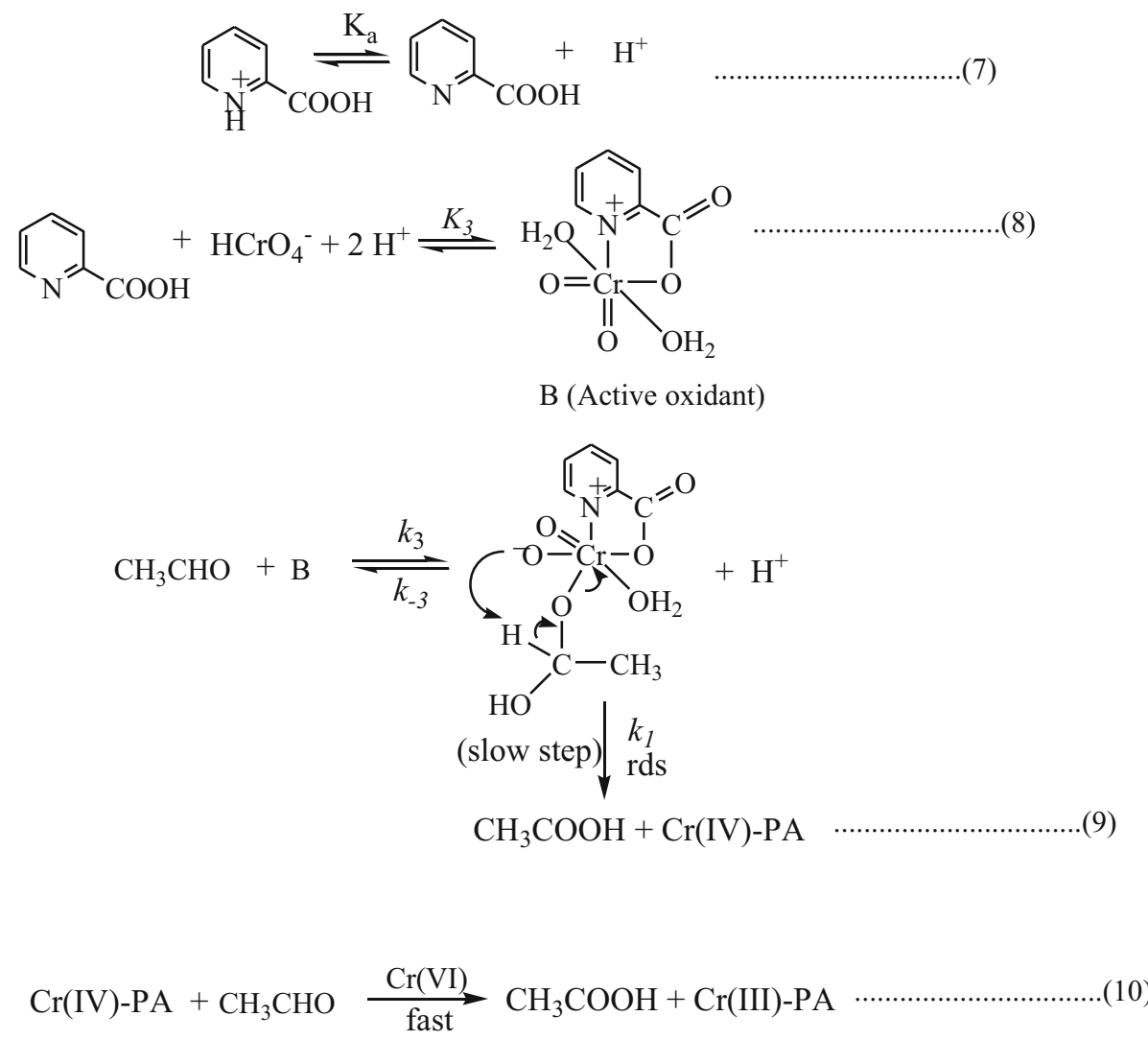

Scheme 2. $\mathrm{Cr}(\mathrm{VI})$ oxidation of acetaldehyde in the presence of picolinic acid. Here, $\mathrm{K}_{\mathrm{a}}=0.25 \mathrm{~mol} \mathrm{dm}^{-3}$ for picolinic acid ${ }^{44} ; \mathrm{rds}=$ rate determining step.

$-\frac{1}{2} \frac{\mathrm{d}\left[\mathrm{HCrO}_{4}^{-}\right]}{\mathrm{HCrO}_{4}^{-}}=\frac{1}{3} k_{2} \mathrm{~K}_{1} \mathrm{~K}_{2}$ [acetaldehyde] $\left[\mathrm{H}^{+}\right]^{2} \mathrm{dt}$

$-\frac{\frac{\mathrm{d}\left[\mathrm{HCrO}_{4}^{-}\right]}{\mathrm{HCrO}_{4}^{-}}}{\mathrm{dt}}=\frac{2}{3} k_{2} \mathrm{~K}_{1} \mathrm{~K}_{2}$ [acetaldehyde $]\left[\mathrm{H}^{+}\right]^{2}$

Here $k_{\mathrm{obs}}=-\frac{\mathrm{d} \ln \left[\mathrm{HCrO}_{4}^{-}\right]}{\mathrm{dt}}$

Hence, $\quad k_{\mathrm{obs}}=k_{2} \mathrm{~K}_{1} \mathrm{~K}_{2}$ [acetaldehyde] $\left[\mathrm{H}^{+}\right]^{2}$

Neutral ester is formed initially, followed by attachment with $\mathrm{H}^{+}$ion to produce the protonated ester, which undergoes decomposition via a cyclic transition state giving rise to the product in the unpromoted path (Scheme 1). The observed rate law of the oxidation reaction can be derived by using the above stoichiometric equation as: $k_{\mathrm{obs}(\mathrm{u})}=(2 / 3) k_{2} \mathrm{~K}_{1} \mathrm{~K}_{2}$ [acetaldehyde $]_{\mathrm{T}}$ $\left[\mathrm{H}^{+}\right]^{2}$.

The rate of $\mathrm{CH}_{3} \mathrm{CHO}$ oxidation by $\mathrm{HCrO}_{4}^{-}$has been significantly enhanced by the involvement of chelating agents PA, bipy and phen. The proposed reaction scheme for the promoted path (Scheme 2) is reasonable and the mechanism was represented in a simple way compared to the earlier reported enzyme catalyzed alcohol oxidation. ${ }^{43}$ The mechanism of the promoted reaction path 


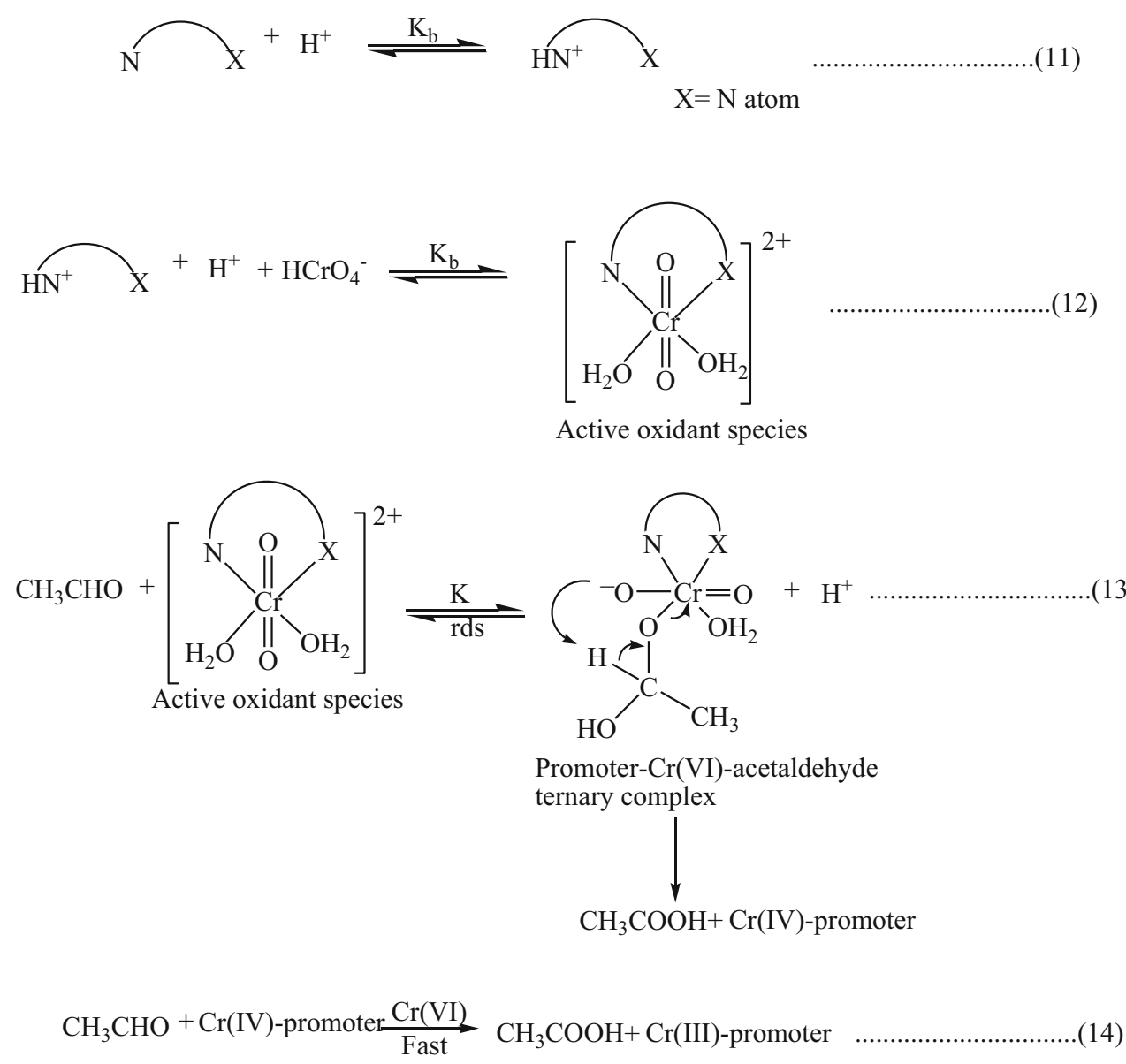

Scheme 3. $\operatorname{Cr}(\mathrm{VI})$ oxidation of acetaldehyde in the presence of bipy and phen. Here $\mathrm{K}_{\mathrm{b}}=2.8 \times 10^{4} \mathrm{~mol} \mathrm{dm}^{-3}$ for bipy and $9.5 \times 10^{4} \mathrm{~mol} \mathrm{dm}^{-3}$ for phen. ${ }^{45}$

for the three different promoters are shown below, in Schemes 2 and 3:

The unreacted $\mathrm{Cr}(\mathrm{VI})$ remains in excess in solution (Schemes 1, 2, 3) which further participates in the reaction between $\mathrm{Cr}(\mathrm{VI})-\mathrm{PA}$ and $\mathrm{CH}_{3} \mathrm{CHO}$ in the fast step to give the final product along with totally reduced $\mathrm{Cr}$ (III) species.

$$
\begin{gathered}
\text { Path I : } \mathrm{Cr}(\mathrm{IV})+\mathrm{Cr}(\mathrm{VI}) \longrightarrow 2 \mathrm{Cr}(\mathrm{V}) \\
2 \mathrm{Cr}(\mathrm{V})+2 \mathrm{~S} \longrightarrow 2 \mathrm{Cr}(\mathrm{III})+\text { Products }
\end{gathered}
$$

In the above-mentioned possible paths, $S$ denotes the substrate acting as a $2 \mathrm{e}$ reductant. In the Watanabe- Westheimer mechanism ${ }^{46}$ (i.e., Path I), the organic substrate acts as a $2 \mathrm{e}$ reductant, and it was established widely for explaining the CrVI oxidation of different organic substrates.

\subsection{Incorporation of the substrate in the micelle-water interface}

The Cr(VI)-promoter complexes for PA, bipy and phen defined as $\mathrm{AO}^{+}$(cationic complex) ${ }^{47}$ are the reactive oxidants for promoted path. Most of the micellar mediated reactions occur either in the Stern layer or at the interfacial junction region between the Stern and the Gouy Chapman layers. The SDS micelle has the aggregation number around sixty and is almost spherical in shape. ${ }^{48}$ The TX-100 micelle is larger in size than the SDS micelle. The core size of non-ionic surfactant TX100 is comparatively larger than that of the SDS micelle. According to the size factor $\mathrm{Cr}(\mathrm{VI})$-phen complex is the larger active-oxidant species than the other two $\mathrm{Cr}(\mathrm{VI})$ promoter species. Larger $\mathrm{Cr}(\mathrm{VI})$-phen complex interacts smoothly and maximum number of $\mathrm{Cr}(\mathrm{VI})$-phen can accumulate within the Stern layer region of the TX-100 micelle. The hydrophobic interaction between the substrate and non-polar tail part of TX-100 micelle can play a vital role to concentrate a huge number of acetaldehyde molecules in the micellar nano-reactor and enhance the rate constant. The interaction between the active oxidants and the polar head group of the micelles also governs the micellar catalysis by TX-100 micelle. But the negative charges on the head group of SDS micelles are partially neutralized in presence of excess 


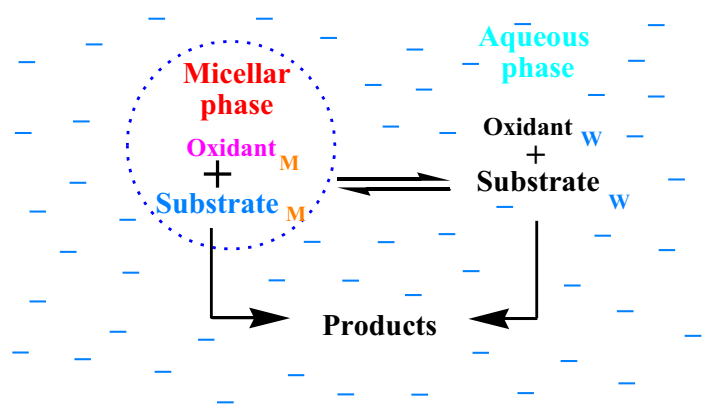

Scheme 4. Partitioning of reactant molecules inside the micelle and aqueous phase.

$\mathrm{H}^{+}$in the reaction medium. So, the less number of active oxidants are available to come in contact with SDS Stern layer due to coulombic attraction. Moreover, the steric factor and hydrophobic interaction plays the dominant role in the acceleration of the reaction rate in the presence of the combination of phen and TX-100. Therefore, the reaction rate follows the order: $k_{\mathrm{obs}(\mathrm{TX}-100)}>k_{\mathrm{obs}(\mathrm{SDS})}>k_{\mathrm{obs}(\text { water })}>k_{\mathrm{obs}(\mathrm{CPC})}$.

The miceller effect on the oxidation of acetaldehyde by $\mathrm{Cr}(\mathrm{VI})$ in the presence of surfactant may be easily discussed in terms of the micellar pseudo-phase model reported by Menger and Portnoy. ${ }^{49}$ According to this model, the reaction scheme for the oxidation in the presence of micelles may be given as in Scheme 4.

\subsection{Interaction of acetaldehyde with TX-100 micelle}

3.5a FTIR study: The FTIR spectra of pure aqueous solution of TX-100 (Figure S5(a)) and substrate-loaded TX-100 (Figure S5(b)) were obtained. The FTIR spectrum of pure TX-100 shows a number of frequencies clearly indicating the presence of several functional groups, which literally supports the complex nature of the TX-100 moiety. The strong broad band centered at $3485 \mathrm{~cm}^{-1}$ is characteristic of $-\mathrm{OH}$ stretch arising from the hydroxyl groups, while the strong peak centered at $2947 \mathrm{~cm}^{-1}$ and $2870 \mathrm{~cm}^{-1}$ are assignable to the asymmetric and symmetric stretching of aliphatic $-\mathrm{CH}_{2}$, respectively. The symmetric stretching bands of benzenoid group vibrations are observed at $1610 \mathrm{~cm}^{-1}$ and $1512 \mathrm{~cm}^{-1}$. The absorption band near $1100 \mathrm{~cm}^{-1}$ has arisen from $\mathrm{C}-\mathrm{O}$ groups of the surfactant. Meanwhile, Figure S3(b) shows considerable shift of the band positions as well as change in intensities. The bands at frequencies in the range 500 to $2000 \mathrm{~cm}^{-1}$ clearly portray the effect of $\mathrm{Cr}(\mathrm{VI})$. It is supportive of the fact that the otherwise free $-\mathrm{OH}, \mathrm{C}-\mathrm{O}$ and other IR active functional groups appear at changed frequencies, which indeed is strong evidence that they are now bound with the substrate molecule.

3.5b ${ }^{1} H$-NMR study: Interactions of acetaldehyde with TX-100 monomers were examined by the chemical shifts in the TX-100 protons in $\mathrm{D}_{2} \mathrm{O}$ (Figure $\mathrm{S} 6$ in SI). TX-100 has 8 different protons such as a, b, $\mathrm{c}, \mathrm{d}, \mathrm{e}, \mathrm{f}, \mathrm{g}$ and $\mathrm{h}$ (Figure 3). Addition of the TX100 surfactant, above its cmc $\left(2 \times 10^{-2} \mathrm{~mol} \mathrm{dm}^{-3}\right)$, with $\mathrm{CH}_{3} \mathrm{CHO}\left(7.5 \times 10^{-3} \mathrm{~mol} \mathrm{dm}^{-3}\right)$ displayed distinct upfield shifts of the 8 different protons of TX-100 (Table S2 in SI). Therefore, in TX-100 medium, polar part of acetaldehyde molecule tends to reside at Stern layer and aliphatic part resides in between the palisade layers of the micelle. ${ }^{50}$

3.5c DLS study: The average hydrodynamic diameter and size distribution of the self-assembled aggregates are determined by dynamic light scattering (DLS). The DLS plot (Figure S7) informs us about the changes in micellar diameter when reactants are present in the reaction medium. This helps us to understand that an interaction take place between substrate (acetaldehyde) and TX-100 with the "Stern layer" of the micelle. The diameter of TX-100 was $334 \mathrm{~nm}$ as found in the plot. Upon interaction of substrate (acetaldehyde) with the outer surface of the aggregates, the diameter of the TX100 micelle increases from $334 \mathrm{~nm}$ to $454 \mathrm{~nm}$.

\section{Conclusions}

All of the above experimental observations on the kinetic and mechanistic studies are summed up as follows: (1) Oxidation of acetaldehyde to acetic acid by

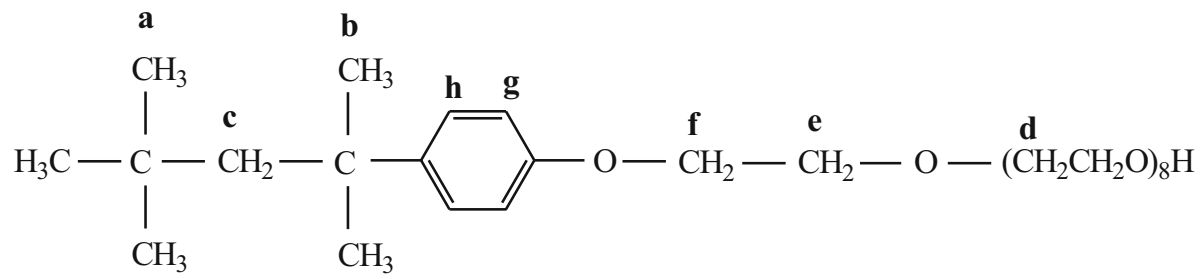

Figure 3. Structure of TX-100. The proton NMR signals $(\mathbf{a}-\mathbf{h})$ are assigned in Table S2. 
$\mathrm{Cr}(\mathrm{VI})$ is speeded up by introducing surfactant. (2) Non-ionic TX-100 micelle was found to be an excellent catalyst compared to the anionic SDS micelle. (3) Micellar catalysis by TX-100 in association with phen promoter increases the reaction rate upto 60 fold.

\section{Supplementary Information (SI)}

The UV-Visible, FTIR, Mass spectra, ${ }^{1}$ H-NMR spectra and DLS data are available as Supplementary Information for this article at www.ias.ac.in/chemsci.

\section{Acknowledgements}

S. Malik acknowledges to UGC-RGNF (F1-17.1/2011-12/ RGNF-SCWES- 6004/(SA-III), India for providing fund. B. Saha acknowledges the CSIR [(Grant- 01(2463)/11/EMRII)], New Delhi, India, for providing funds in the form of project. Authors thank The University of Burdwan for providing the infrastructural facilities.

\section{References}

1. Mondal M H, Malik S, Roy A, Saha R and Saha B 2015 Modernization of surfactant chemistry in the age of Gemini and bio- surfactants: a review RSC Adv. 592707

2. Mondal M H, Malik S, De S, Bhattacharyya S S and Saha B 2017 Employment and resurrection of surfactants in bipyridine promoted oxidation of butanal using bivalent copper at NTP Res. Chem. Intermed. 431651

3. Choudhary V R, Dumbre D K and Narkhede V S 2012 Solvent-free oxidation of aldehydes to acids by TBHP using environmental-friendly $\mathrm{MnO}_{4}^{-}$exchanged $\mathrm{Mg}-\mathrm{Al}$ hydrotalcite catalyst J. Chem. Sci. 124835

4. Kydd R, Teoh W Y, Scott J, Ferri D and Ama R 2009 Probing surface properties and reaction intermediates during heterogeneous catalytic oxidation of acetaldehyde Chem. Cat. Chem. 1286

5. Sen Gupta K K, Adhikary M, Mandal S K and Sen Gupta S 1987 Kinetics and mechanism of the oxidation of acetaldehyde by chromic acid in perchloric acid Transit. Met. Chem. 12152

6. Kamble D L and Nandibewoor S T 1998 Osmium(VIII)/ruthenium(III) Catalysis of periodate oxidation of acetaldehyde in aqueous alkaline medium J. Phys. Org. Chem. 11171

7. Daviadek T, Devaud S P, Robert F and Blank I 2006 Sugar fragmentation in the maillard reaction cascade: isotope labeling studies on the formation of acetic acid by a hydrolytic â-Dicarbonyl cleavage mechanism J. Agric. Food Chem. 546667

8. (a) Myers R L 2006 In The 100 Most Important Chemical Compounds: A Reference Guide (Westport, CT: Greenwood Press:); (b) Pybus D and Sell C (Eds.) 2006 “4.2.15 Bicyclic Monoterpenoids". In The Chemistry of Fragrances: From Perfumer to Consumer. $2^{\text {nd }}$ ed. (Great Britain: RSC Paperbacks Series)

9. Banerji J, Kotai L, Sharma P K and Banerji K K 2012 Kinetics and mechanism of the oxidation of substituted benzaldehydes with Bis(Pyridine) silver permanganate Eur. Chem. Bull. 1135

10. Ghosh A, Saha R, Mukherjee K, Sar P, Ghosh S K, Malik S, Bhattacharyya S S and Saha B 2014 Rate enhancement via micelle encapsulation for room temperature metal catalyzed $\mathrm{Ce}(\mathrm{IV})$ oxidation of p-chlorobenzaldehyde to $\mathrm{p}$-chlorobenzoic acid in aqueous medium at atmospheric pressure J. Mol. Liq. 19081

11. Henehan G T M and Oppenheimer N J 1993 Horse liver alcohol dehydrogenase-catalyzed oxidation of aldehydes: dismutation precedes net production of reduced nicotinamide adenine dinucleotide Biochem. 32735

12. Malik S, Ghosh A and Saha B 2016 Hetero-aromatic nitrogen base promoted $\mathrm{Cr}(\mathrm{VI})$ oxidation of butanal in aqueous micellar medium at room temperature and atmospheric pressure J. Solution Chem. 45109

13. Rai K K, Kannaujia R K, Rai K and Singh S 2013 Oxidation of benzaldehyde by quinolinium chloro chromate in presence of Ctab in sulphuric acid medium Orient. $J$. Chem. 291071

14. Sekar K G and Periyasamy S K 2013 Oxidation of thioacids by quinaldinium fluorochromate Arabian $J$. Chem. 9574

15. Mansoor S S and Shafi S S 2010 Oxidation of benzhydrol by tributylammonium chlorochromate: a kinetic and mechanistic study React. Kinet. Mech. Catal. 10021

16. Chimatadar S A, B K Sangappa and Nandibewoor S T 2002 A kinetic and mechanistic study of thallium(I) oxidation by quinolinium dichromate (QDC), a new oxidant Transit. Met. Chem. 27704

17. Chimatadar $\mathrm{S}$ A, Basavaraj $\mathrm{T}$ and Nandibewoor $\mathrm{S}$ T 2006 Mechanistic study of quinoliniumdichromate (QDC) oxidation of mercury(I) in aqueous sulfuric acid in the presence of micro amounts of palladium(II) Autocatalysis in catalysis Polyhedron 252976

18. Kulkarni R M, Bilehal D C and Nandibewoor S T 2004 Oxidation of isoniazid by quinolinium dichromate in an aqueous acid medium and kinetic determination of isoniazid in pure and pharmaceutical formulations Anal. Sci. 20743

19. Dayanandhan, R and Subramani K 2016 Kinetics and Mechanism of Oxidation of Lactic Acid by Tripropylammonium Halochromates $(\mathrm{X}=\mathrm{F}, \mathrm{Cl})$ in Micellar medium Asian J. Res. Chem. 9170

20. Khan A A P, Mohd A, Bano S and Siddiqi K S 2011 Kinetics and mechanism of deamination and decarboxylation of 2-aminopentanedioic acid by quinolinium dichromate (QDC) in aqueous perchloric acid medium Ind. Eng. Chem. Res. $\mathbf{5 0} 9883$

21. Das A K 2004 Micellar effect on the kinetics and mechanism of chromium(VI) oxidation of organic substrates Coord. Chem. Rev. 24881

22. Sorella G L, Strukul G and Scarso A 2015 Recent advances in catalysis in micellar media Green Chem. 17 644

23. Malik S, Mondal M H, Ghosh A, De S, Mahali K, Bhattacharyya S S and Saha B 2016 Combination of sodium dodecylsulfate and 2,2'-bipyridine for hundred fold rate enhancement of chromium(VI) oxidation of malonic acid at room temperature: a Greener approach J. Solution Chem. 451043 
24. Malik M A, Al-Thabaiti S A, Al-Youbi A O and Khan Z 2011 Micellar and salt kinetic effects upon the reaction $\mathrm{MnO}_{4}^{-}+$EDTA J. Saudi Chem. Soc. 15221

25. Jakubowska A 2010 Interactions of different counter ions with cationic and anionic surfactants J. Colloid Interface Sci. 346398

26. Zhou M, Li S, Zhang Z, Luo G and Zhao J 2016 Synthesis of oligomer betaine surfactant (DDTPA) and rheological properties of wormlike micellar solution system $J$. Taiwan Inst. Chem. Eng. 661

27. Bunton C A 2005 Micellar charge effects as mechanistic criteria in spontaneous hydrolyses of acid chlorides $J$. Phys. Org. Chem. 18115

28. Yunes S J, Gillitt N D and Bunton C A 2005 Examination of the pseudophase model of monomer-micelle interconversion in cetylpyridinium chloride J. Colloid Interface Sci. 281482

29. Kabir-ud-Din A, Morshed M A and Khan Z 2002 Influence of sodium dodecyl sulphate/TritonX-100 micelles on the oxidation of D-fructose by chromic acid in presence of $\mathrm{HClO}_{4}$ Carbohydr. Res. 3371573

30. Malik S, Saha D, Mondal, M H, Sar P, Ghosh A, Mahali K and Saha B 2017 Micellar effect on hetero-aromatic nitrogen base promoted chromic acid oxidation of 1,3propanediol in aqueous media at room temperature $J$. Mol. Liq. 225207

31. Sumathi T, Shanmugasundaram $P$ and Chandramohan G 2011 A kinetic and mechanistic study on the silver (I)-catalyzed oxidation of 1-alanine by cerium (IV) in sulfuric acid medium Arabian J. Chem. 4427

32. Zhai Y, Liu H, Liu B, Liu Y, Xiao J and Bai W 2007 Kinetics and mechanism of ruthenium(III) catalyzed oxidation of tetrahydrofurfuryl alcohol by cerium(IV) in sulfuric acid media Transition Met. Chem. 32570

33. Wu C, Li N J, Chen K C and Hsu HF 2014 Determination of critical micelle concentrations of ionic and nonionic surfactants based on relative viscosity measurements by capillary electrophoresis Res. Chem. Intermed. 402371

34. Ghosh S K, Saha R, Mukherjee K, Ghosh A, Bhattacharyya S S and Saha B 2012 Micellar catalysis on 1,10-phenanthroline promoted chromic acid oxidation of propanol in aqueous media J. Korean Chem. Soc. 56 164

35. Roldán V, González J C, Santoro M, García S, Casado N, Olivera S, Boggio J C, Salas-Peregrin J M, Signorella $\mathrm{S}$ and Sala L F 2002 Kinetics and mechanism of the oxidation of disaccharides by $\mathrm{Cr}(\mathrm{VI})$ Can. J. Chem. 80 1676

36. Saha R, Ghosh A and Saha B 2013 Kinetics of micellar catalysis on oxidation of $\mathrm{p}$-anisaldehyde to $\mathrm{p}$-anisic acid in aqueous medium at room temperature Chem. Eng. Sci. 9923

37. Ghosh S K, Basu A, Saha R, Ghosh A, Mukherjee K and Saha B 2012 Micellar catalysis on picolinic acid promoted hexavalent chromium oxidation of glycerol $J$. Coord. Chem. 651158
38. Basu A and Saha B 2010 Kinetic studies on hexavalent chromium reduction Am. J. Anal. Chem. 125

39. Malik S, Ghosh A and Saha B 2016 Optimal process condition for room temperature hetero-aromatic nitrogen base promoted chromic acid oxidation of $\mathrm{p}$ chlorobenzaldehyde to p-chlorobenzoic acid in aqueous micellar medium at atmospheric pressure Tenside Surf. Det. 5394

40. Malik S, Ghosh A, Mukherjee K and Saha B 2014 Combination of best promoter and micellar catalyst for $\mathrm{Cr}(\mathrm{VI})$ oxidation of lactose to lactobionic acid in aqueous medium at room temperature Tenside Surf. Det. 51 325

41. Perez-Benito E and Rodenas E 1991 Influence of sodium dodecyl sulfate micelles on the oxidation of alcohols by chromic acid Langmuir 7232

42. Ansari W H, Fatma N, Panda M and UD-Din K 2013 Solubilization of polycyclic aromatic hydrocarbons by novel biodegradable cationic gemini surfactant ethane-1,2diyl bis(N,N-dimethyl-N-hexadecylammoniumacetoxy) dichloride and its binary mixtures with conventional surfactants Soft Matter 91478

43. Shearer G L, Kim K, Lee K M, Wang C K and Plapp B V 1993 Alternative pathways and reactions of benzyl alcohol and benzaldehyde with horse liver alcohol dehydrogenase Biochem. 3211186

44. Saha R, Ghosh A, Sar P, Saha I, Ghosh S K, Mukherjee $\mathrm{K}$ and Saha B 2013 Combination of best promoter and micellar catalyst for more than kilo-fold rate acceleration in favor of chromic acid oxidation of D-galactose to Dgalactonic acid in aqueous media at room temperature Spectrochim. Acta Part A 116524

45. Islam M, Saha B and Das A K 2005 Kinetics and mechanism of 2,2' -bipyridyl and 1,10-phenanthrolinecatalysed chromium(VI) oxidation of d-fructose in aqueous micellar media J. Mol. Catal. A: Chem. 236260

46. Watanabe W and Westheimer F H 1949 The kinetics of the chromic acid oxidation of isopropyl alcohol: the induced oxidation of manganous ion J. Chem. Phys. 17 61

47. Khan Z 2002 Kinetics and mechanism of ethylenediaminetetraacetic acid-, 2,2'-bipyridyl-, and 1,10phenanthroline-assisted chromium(VI) oxidation of 2propanol Transit. Met. Chem. 27832

48. Chaudhuri A, Haldar S and Chattopadhyay A 2009 Organization and dynamics in micellar structural transition monitored by pyrene fluorescence Biochem. Biophys. Res. Commun. 390728

49. Menger F M and Portnoy C E 1967 Chemistry of reactions proceeding inside molecular aggregates $\mathrm{J}$. Am. Chem. Soc. 894698

50. Patel V, Ray D, Aswal V K and Bahadur P 2014 Triton $\mathrm{X}-100$ micelles modulated by solubilized cinnamic acid analogues: the $\mathrm{pH}$ dependant micellar growth Colloids Surf. A $\mathbf{4 5 0} 106$ 